\title{
Por uma outra forma de (re)pensar as Relações Internacionais: hegemonia e criação de consenso
}

\author{
Towards another way of (re)thinking International Relations: hegemony and consensus building
}

DOI: https://doi.org/10.22456/2178-8839.105342

Camila Feix Vidal

Universidade Federal de Santa Catarina, Florianópolis, Brasil

camilafeixvidal@gmail.com

Luan Correa Brum

Universidade Federal de Uberlância, Uberlância, Brasil

luan.brum1996@hotmail.com

\section{Resumo}

Esse trabalho busca repensar as Relações Internacionais a partir de lentes sociológicas e neogramscianas levando em conta o papel da hegemonia estadunidense no âmbito latino americano através de práticas de consenso. Esse estudo apresenta estratégias de internacionalização de uma classe dominante na promoção do modelo capitalista neoliberal estadunidense utilizando-se de instituições e de indivíduos pertencentes a essa mesma classe. Para isso, se analisa o papel que o National Endowment for Democracy e a Atlas Network vem desempenhando na América Latina enquanto veículos de estratégia para manutenção da hegemonia estadunidense. Como resultado, encontramos uma relação de proximidade entre esses institutos e o Departamento de Estado além de uma relação de simbiose entre os institutos latino-americanos e os estadunidenses na divulgação e naturalização do ideário neoliberal. Mais do que apresentar o laço entre duas camadas dominantes e seus esforços na promoção de uma agenda neoliberal, esse estudo nos incita a refletir acerca de práticas e conceitos relativamente marginalizados nas Relações Internacionais como hegemonia, formação de consenso e o papel de ideologias como o neoliberalismo na manutenção da estrutura econômica dominante.

Palavras-chave: Hegemonia; Estados Unidos; América Latina.

\begin{abstract}
This work is a theoretical effort that aims to contribute to rethinking IR from sociological and neogramscian lenses focusing on the United States hegemonic role in Latin America through consensus practices. This study presents the strategies of internationalization by an economic and dominant social class promoting the US capitalist system using, for that, institutions and individuals part of a certain economic and dominant class. To do so, we analyze the role that the National Endowment for Democracy and Atlas Network have been developing in Latin America while vehicles for a strategy of US hegemonic maintenance. As a result, we find an intrinsic relationship between these institutes and the State Department as well as between Latin American and US institutes and when delivering and naturalizing the neoliberal ideal. More than just presenting the ties between two dominant fractions and their efforts on promoting a neoliberal agenda, this study incite us to reflect upon practices and concepts relatively marginalized in International Relations such as hegemony, consensus building and the role of ideologies such as neoliberalism that maintain the dominant economic structure.
\end{abstract}

Keywords: Hegemony; United States; Latin America. 


\section{Introdução}

Não é novidade o papel que os Estados Unidos exercem, direta e indiretamente, na América Latina. Se as intervenções militares desse país na região tiveram ênfase no período da Guerra Fria; intervenções indiretas se fortalecem quando do fim desse período. Ainda que menos visíveis, as intervenções atuais não são menos sutis - continuam fazendo parte de um projeto hegemônico dirigido por uma classe econômica dominante estadunidense (e, portanto, dirigente) que encontra legitimidade e respaldo nos seus congêneres latino americanos ${ }^{1}$. Assim, esse estudo tem como ponto de partida o entendimento de que a classe dominante legitima seu papel ao persuadir a sociedade a pensar de uma determinada forma - uma que reproduz a desigualdade econômica e social do status quo seja através da força, seja através do consenso (GRAMSCI, 1971).

Nesse sentido, se entende que a abordagem estadocêntrica prevalecente na área de Relações Internacionais (RI) limita a compreensão da dinâmica existente no âmbito internacional e é nociva para as classes subalternas. Dito de outra forma, ao centralizarmos no "Estado" enquanto unidade monolítica e formuladora de um único interesse nacional, pouco levamos em conta o papel que a classe econômica e dirigente detém, bem como sua relação com outras classes ao redor do globo. O "interesse nacional” é o interesse de uma classe dominante na manutenção dos seus privilégios que encontra ressonância (ou resistência) em outras classes e regiões. O foco, assim, passa da ameaça à sobrevivência de um estado versus outro estado, para a ameaça à manutenção de uma classe economicamente dominante versus outra classe economicamente subalterna. Nesse sentido, o âmbito das ideais na construção do consenso recebe espaço privilegiado.

Esse trabalho busca ser uma ponte entre o já estabelecido consenso acerca do domínio acadêmico estadunidense no âmbito das Relações Internacionais (HOFFMAN, 1977; TICKNER, 2003; ACHARYA; BUZAN, 2010; TICKNER; INOUE, 2016; VILLA et al, 2017) e a empiria de um estudo pontual sobre essa dominação na América Latina. Se, como argumentam Bourdieu e Wacquant (1992), a teoria sem empiria é vazia e a empiria sem teoria é cega; o esforço do trabalho aqui apresentado é o de relacionar um estudo empírico a partir de lentes sociológicas e Gramscianas no âmbito das RI que enfatiza a importância de mecanismos de criação de consenso na manutenção de uma classe social.

O movimento em direção ao uso da abordagem Gramsciana aplicada às RI tem sido contínuo, mas lento - dada a preponderância de teorias e autores Realistas e Liberais na área (VILLA et al, 2017). Felizmente alguns autores vem retomando (ou inaugurando) estudos baseados na relação entre ideologia (e superestrutura) e a estrutura capitalista (PIKETTY, 2020; ALPEROVITZ; DALY, 2010). A partir deste arcabouço teórico, há a possibilidade de desenvolver pesquisas direcionadas às inter-relações existentes entre as práticas desenvolvidas por grupos dominantes dentro de um determinado Estado e a forma como as mesmas se relacionam e são reproduzidas no sistema internacional. Assim como é difícil tratar da história da América Latina sem levar em conta o papel dos Estados Unidos na região, da mesma forma é bastante limitado um estudo acerca do (sub)desenvolvimento latino americano sem levar em consideração a dimensão da ideologia na criação de consenso para a manutenção do modelo econômico neoliberal hegemônico.

Utiliza-se nessa pesquisa da concepção de hegemonia desenvolvida por Antonio Gramsci entendendo-a como um conjunto de funções de domínio e direção exercidas por uma determinada classe social dominante sobre o restante da sociedade utilizando-se de uma combinação de força e consenso. Assim, a estratégia da classe dominante nos EUA consistiria em fazer prevalecer a internacionalização e a naturalização de saberes e valores que se assentam em seus interesses na forma de “interesses nacionais". Apoiados em uma espécie de "saber técnico" (COX, 1981) no qual as relações passam a serem definidas em termos de centro x periferia - estando esta última destinada a mera reprodução dos saberes e conhecimentos desenvolvidos pelo centro; e levando em consideração que "toda teoria é sempre para alguém e para

\footnotetext{
${ }^{1}$ Para Gramsci, a supremacia de uma classe social se dá pelo domínio e pela direção intelectual e moral. Assim, "um grupo social domina os grupos adversários que visa liquidar ou a submeter inclusive com a força armada, e dirige os grupos afins e aliados” (GRAMSCI, 2002, p. 62). Essa classe social normalmente é dirigente antes de ser dominante (ou seja, antes de alcançar formalmente os espaços políticos).
} 
algum propósito" (COX, 1981, p. 87); compreende-se que as ideologias desenvolvidas por este centro estariam ancoradas em uma posição de domínio, dada uma diferença em termos de riquezas materiais e produção ideológica desenvolvida.

Como consequência, há uma circulação de textos e teorias advindas dos EUA em relação à periferia que contribuem para a dominação em matéria cultural, assim como para a imposição do princípio de dominação dominante ou, como Bourdieu destaca, "para a imposição de uma definição específica do exercício legitimo da atividade intelectual” (BOURDIEU, 2002, p. 11). Dentro deste quadro, a internacionalização e naturalização do neoliberalismo - entendido a partir de Dardot e Laval (2016) como um sistema não apenas econômico, mas também social - se apresentaria como uma importante dimensão da estratégia de domínio e direção de uma classe dominante estadunidense no âmbito internacional. De forma a fazer propagar o ideário neoliberal pelo globo, tem-se observado um desenvolvimento cada vez mais acentuado de centros de think tanks como "aparelhos privados de hegemonia” (GRAMSCI, 2007). Ou seja, organizações voluntárias por parte da sociedade civil que se apresentam como autônomas e não partidárias, mas que estão relacionadas à classe econômica dominante na manutenção e na propagação do sistema de dominação. Dentro desses, destacam-se os estadunidenses Atlas Network e National Endowment for Democracy.

Esse trabalho busca apresentar as redes de relação e as práticas destes institutos na manutenção de uma classe econômica dirigente e cooptação de outra classe em países latino americanos a partir de dados primários disponibilizados nos websites desses institutos e de bibliografia especializada. Ainda que esse seja um esforço teórico para se repensar as RI, utiliza-se desses institutos como objeto de relação empírica. Entende-se que a classe dominante estadunidense busca através desses institutos exercer práticas de domínio e direção por meio da conformação de institutos condizentes com os interesses e objetivos próprios promovendo políticas econômicas que sejam favoráveis a essa mesma classe. Como a condição de grande potência está relacionada com a "possibilidade de imprimir a atividade estatal uma direção autônoma, que influencie e repercuta sobre os outros Estados” (GRAMSCI, 2007, p. 55), cria-se um sistema de alianças com outros países e grupos de forma a estender seus interesses para além de suas fronteiras. Assim, transportam-se visões de mundo da classe dominante para os dominados contribuindo para a manutenção de relações desiguais e de dependência. Como

observa Stephen Gill, “central para a manutenção da hegemonia é um sistema de regras baseado mais em aspectos consensuais do poder do que na coerção direta” (GILL, 2008, p. 14). Nesse sentido, a hegemonia a nível internacional trata se de uma expansão natural daquela hegemonia no âmbito interno do Estado.

Por fim, esse estudo nos incita a refletir acerca de práticas e conceitos relativamente marginalizados nas Relações Internacionais como hegemonia, formação de consenso e o papel da ideologia na manutenção da estrutura econômica dominante. Além disso, nos faz questionar o papel predominante que o "Estado", enquanto entidade monolítica e detentora de um único “interesse nacional”, recebe nessa mesma área. Em específico, nos faz retomar abordagens teóricas fundamentais para entendermos o papel das classes dominantes na criação de consensos para países e classes subalternas com o objetivo de manutenção dessas mesmas estruturas hegemônicas.

\section{A construção hegemônica}

A existência de hegemonia(s) na ordem mundial se apresenta como um fato. Na concepção Gramsciana, o "Estado" é entendido de modo ampliado onde a sociedade civil é elemento presente e atua de forma fundamental na sustentação da dominação de classe. Diante disso, a condição de potência hegemônica estaria relacionada com a “possibilidade de imprimir a atividade estatal uma direção autônoma, que influa e repercuta sobre os outros Estados” (GRAMSCI, 2007, p. 55) criando-se para tanto um sistema de alianças com outros grupos, de forma a estender seus interesses para além de suas fronteiras. De forma a atender este objetivo, as classes dominantes presentes nos estados hegemônicos se utilizam de uma espécie de "imperialismo cultural”, ou seja, o "poder de universalizar os particularismos associados a uma tradição histórica singular, tornando-os irreconhecíveis como tais” (BOURDIEU; WACQUANT, 2002, p. 
15). Esse imperialismo - informal e, por vezes, imperceptível - é um tipo de violência simbólica pelo qual Bourdieu repensa e elabora o conceito gramsciano de hegemonia (EAGLETON, 1996). Sem embargo, a hegemonia situa-se no papel desempenhado e nos recursos adquiridos por uma classe econômica dominante e, portanto, política e dirigente em um determinado Estado. Assim, quando se fala em "Estado hegemônico" se está considerando a classe econômica dirigente desse estado. A hegemonia é característica dessa classe dominante, não propriamente do “Estado”.

Para Gramsci, a hegemonia é entendida como um conjunto de funções de domínio e direção exercidas por uma determinada classe social dominante sobre o restante da sociedade que se utiliza de uma "combinação da força e do consenso que se equilibram de modo variado, sem que a força suplante em muito o consenso” (GRAMSCI, 2007, p. 73). De modo mais específico, seria "toda uma gama de estratégias práticas mediante as quais um poder dominante obtém, daquele a quem subjuga, o consentimento em sua dominação” (EAGLETON, 1996, p. 198). Assim, “central para a manutenção da hegemonia é um sistema de regras baseado mais em aspectos consensuais do poder do que na coerção direta" (GILL, 2008, p. 14). Dentro deste quadro, o Estado se apresenta como um espaço em que os detentores de diferentes tipos de capitais lutam em torno do capital simbólico que advém da capacidade estatal em produzir e impor a legitimidade de uma dada ordem social (BOURDIEU, 1996, 1998). Além da capacidade simbólica que contribui para assegurar a dominação de uma classe sobre a outra, o Estado ainda se configura como detentor do monopólio da violência física contribuindo para a adequação do restante da sociedade em torno da estrutura econômica vigente e de seus interesses hegemônicos. Nesse sentido, a hegemonia pressupõe uma luta constante por sua afirmação e conquista dos meios materiais e simbólicos para sua manutenção.

A partir de lutas travadas entre classes e facções de classes das sociedades nacionais, conformam-se estratégias de importação e exportação de normas e práticas estando a periferia destinada à importação de valores exportados pelo centro. Assim,

O conceito hegemônico de ordem mundial é fundado não apenas sobre a regulação do conflito interestatal, mas também sobre uma sociedade civil globalmente concebida, isto é, um modo de produção de extensão global que produz elos entre as classes sociais dos países abrangidos por ela (COX, 1993, p. 61).

Nesse sentido, a hegemonia a nível internacional trata-se de expansão natural daquela hegemonia conformada no âmbito interno do próprio Estado. Logo, observa-se que as práticas de dominação exercidas por determinado grupo hegemônico no âmbito nacional seriam transportadas por intermédio do Estado, que se utiliza de aparato coercitivo para assegurar legalmente a disciplina dos grupos que não consentem (GRAMSCI, 1989). O Estado atua no sistema internacional como um representante dos interesses daqueles agentes que ocupam as posições dominantes nos espaços nacionais. Dessa forma, essa classe dominante exerce estratégias de universalização de seus objetivos e de visões de mundo em outros demais países e classes na forma de "doxa": "um ponto de vista particular, o ponto de vista dos dominantes, que se apresenta e se impõe como ponto de vista universal” (BOURDIEU, 1996, p. 120). Assim,

As frações dominantes, cujo poder assenta no capital econômico, têm em vista impor a legitimidade da sua dominação quer por meio da própria produção simbólica, quer por intermédio dos ideólogos conservadores os quais só verdadeiramente servem os interesses dos dominantes. (BOURDIEU, 1996, p. 12)

Outrossim, esse espaço transnacional construído a partir de estratégias de internacionalização desenvolvidas por grupos dominantes são aceitas por seus congêneres no exterior porque a eles também lhes beneficia:

Esse espaço transnacional existe porque internacionalizar gera uma série de benefícios em nível nacional e porque os importadores também têm algo a ganhar. Os agentes que ocupam as posições dominantes nos espaços nacionais e transnacionais são muitas vezes, se não as mesmas pessoas, agentes muito semelhantes, recorrendo a uma multiplicidade de capital (BIGO; MADSEN, 2011, p. 222). 
Existe, assim, uma proximidade entre as classes dominantes nos diferentes países o que corrobora para convergências de interesses, o que aponta para o surgimento de uma classe dominante global de modo que a construção de um espaço transnacional de instituições e práticas contribui para que estes grupos propaguem as suas visões de mundo de maneira interconectada (BIGO, 2011).

Processo dinâmico, a manutenção da hegemonia carece de atualização de estratégias de atuação para sua permanência. Ainda que o uso da coerção na forma de intervenções militares por parte dos EUA na América Latina tenha sido frequente em grande parte do século XX; hodiernamente essas intervenções vem assumindo novas formas de relacionamento entre estruturas ainda mais extensas e interconectadas de modo que a dominação estadunidense no sistema internacional não se limitaria à utilização da coerção e de seus recursos materiais, mas de igual maneira do consenso através da articulação entre instituições sociais e ideologia voltadas para a obtenção de legitimação de seu domínio e direção (COX, 1981, 1993). Nesse sentido, a estratégia dos EUA enquanto poder hegemônico consiste em fazer prevalecer no âmbito internacional o domínio de ideologias e valores que representem os seus interesses numa forma de imperialismo cultural e, de igual forma, os da classe dirigente que o mesmo representa numa espécie de "hegemonia indireta e aparentemente consensual” (BRZEZINSKI, 1998, p. 36).

\section{A formação do consenso e aparelhos privados de hegemonia}

Reação teórica e política contra o estado de bem-estar social que se desenvolvia no pós-Segunda Guerra Mundial, o neoliberalismo apresenta-se enquanto ideologia que reproduz um sistema de princípios econômicos, políticos e culturais que corroboram para a manutenção e a conservação de uma ordem dominada pelos interesses de uma classe dominante. Apropriando-se da ideia da globalização, vem contribuindo para a expansão dos interesses e domínio dos EUA no âmbito global ao mesmo tempo que promove um retorno do individualismo em oposição a uma visão coletivista da sociedade depreciando, para tanto, a coisa pública. Para isso, determinados atores exercendo papel de “intelectuais orgânicos” - ou seja, grupos sociais que criam para si e de modo orgânico "uma ou mais camadas de intelectuais que lhe dão homogeneidade e consciência da própria função, não apenas no campo econômico, mas também no social e no político” (GRAMSCI, 1989, p. 3); foram fundamentais. De fato, um dos primeiros exemplos que Gramsci se debruça nas suas observações é o "empresário capitalista” que cria ao mesmo tempo e com objetivos próprios, o “técnico”, o “especialista em economia”, o "especialista em política” e o organizador de um novo consenso na sociedade (GRAMSCI, 2001).

O neoliberalismo assume uma importante dimensão dentro da estratégia dos Estados Unidos enquanto poder hegemônico. Além de servir aos interesses de uma classe dominante estadunidense (e seus congêneres no exterior), atende aos objetivos da camada empresarial que a mesma representa utilizando-se, para tanto, de um discurso que privilegia premissas pró-empresariado e que busca se utilizar de um conjunto de palavras e simbolismos que adotam uma aparência de inevitabilidade. Assim,

\footnotetext{
"Ouve-se dizer por toda a parte, o dia inteiro" — aí reside a força desse discurso dominante — que não há nada a opor à visão neoliberal, que ela consegue se apresentar como evidente, como desprovida de qualquer alternativa. Se ela comporta essa espécie de banalidade, é porque há todo um trabalho de doutrinação simbólica do qual participam passivamente os jornalistas as ou os simples cidadãos e, sobretudo, ativamente, um certo número de intelectuais (BOURDIEU, 1998, p. 27).
}

Desse modo, a supremacia estadunidense se caracteriza pelo esforço de sua classe dominante no estabelecimento de uma forma neoliberal disciplinar de globalização (GILL, 2005, p. 29). Contudo, essa condição não se trata de efeito direto (coercitivo), mas de ações empreendidas por agentes inseridos em think tanks neoliberais que objetivam, a partir de uma série de estratégias, a disseminação desse ideário no globo. Não obstante, estes buscam se apresentar como 
apartidários separando, assim, o público do privado e encobrindo interesses materiais com uma espécie de "véu da neutralidade" que a sua credencial profissional e acadêmica os legítima (FISCHER; PLEHWE, 2013). Desse modo, estas organizações ocupariam uma posição intermediária dentro do espaço social encontrando-se entre a autoridade baseada na consagração intelectual de um lado, e a proximidade com o poder político e econômico de outro; de forma que em suas atividades gozariam de uma espécie de autoridade intelectual que visa acesso político. Um caso exemplar é a estadunidense Atlas Network.

\section{Atlas Network}

A Atlas atua como um think tank guarda-chuva voltado a orientar a criação e a manutenção de institutos neoliberais chamados de "parceiros". Assim, por intermédio da disseminação de postulados neoliberais, a Atlas busca "fortalecer uma rede global de organizações independentes da sociedade civil, que promovam a liberdade individual e removam as barreiras ao desenvolvimento humano" (ATLAS, 2019). De fato, o nome “Network” é tanto substantivo próprio quanto adjetivo já que a importância da Atlas se dá na forma de orientação e apoio financeiro e logístico na criação e manutenção de institutos congêneres ao redor do globo.

A Atlas se insere dentro de um processo histórico na primeira metade do século XX na Inglaterra e Estados Unidos, liderado por indivíduos como Friederich Hayek, Ludwing Von Mises e Milton Friedman que visava articular uma frente que se opusesse ao Keynesianismo. Na década de 80, com a chegada de Margareth Thatcher no Reino Unido e de Ronald Reagan nos Estados Unidos, o contexto internacional é favorável para que o discurso e as políticas neoliberais fossem internacionalizados. Assim, em 1981, o britânico Antony Fisher cria em Washington DC a Atlas Economic Research Foundation (atual Atlas Network) que passa a articular a criação e a manutenção de uma série de institutos neoliberais em todos os continentes como uma espécie de "nó central de transmissão de fundos, pessoas e outros recursos que demanda o fluxo transnacional de ideias e políticas neoliberais" (FISCHER; PLEHWE, 2013, p. 77).

Com a ascensão do argentino Alex Chafuen² à presidência da Atlas em 1991, o instituto foca suas atividades na América Latina. Atualmente conta com 95 parceiros na região além do primeiro centro regional: o Atlas Network's Center for Latin America, criado em 2018. Dirigido por Roberto Salinas León ${ }^{3}$, este centro busca desenvolver na região uma frente em prol de uma agenda política e econômica neoliberal a partir de destinação de recursos financeiros, treinamento e suporte necessário para que institutos promovam agendas e políticas públicas neoliberais. Só no ano passado, a Atlas enviou US\$ 1.277.859,00 em recursos financeiros para seus parceiros na região (ATLAS, 2019).

A Atlas não desempenha um papel inocente. Busca influenciar na implementação de agendas econômicas e no curso das mudanças políticas na América Latina. No Brasil há que se considerar a relação do Movimento Brasil Livre (MBL) com a Atlas e o papel desempenhado pelo grupo no impeachment da então presidenta Dilma Rousseff. Na Argentina, a Organização Pensar, atrelada à Atlas, desempenhou importante papel no anti-kirshnerismo e foi incorporada posteriormente ao partido do então presidente Macri. Em Honduras, a Fundação Eleutera foi ativa no golpe hondurenho mantendo estreitos laços com a Atlas, de quem recebeu recursos. Por fim, na Venezuela, desde 1998 o Cedice Libertad recebeu apoio financeiro na campanha por uma mudança de governo (AHARONIAN; RANGEL, 2018).

Com relação ao Brasil, não é à toa que o crescimento no número de institutos parceiros da Atlas converge com a manutenção de governos relativamente desenvolvimentistas, como os petistas. De fato, durante o governo Lula (20032011) e no discorrer do governo Rousseff (2011-2016) surgem institutos liberais como Instituto Millenium (2005), Instituto Ludwing von Mises (2007), MBL (2014), entre outros, que logo se articulariam com seus congêneres fundados nos anos 80

\footnotetext{
${ }^{2}$ Fundador e presidente do Conselho do Hispanic American Center For Economic Research criado em 1996 com sede em Washington, D.C. que se dedica a promover as ideias ultraliberais na América Hispânica e entre hispano-americanos que vivem nos Estados Unidos (BAGGIO, 2016).

${ }^{3}$ Dirige o Fórum Empresarial do México e a Aliança Alamos.
} 
no Brasil e com a Atlas nos Estados Unidos. Assim, os “combatentes da liberdade”, afiliados à Atlas, "tornaram-se os principais organizadores contra o Partido dos Trabalhadores e a presidência de Dilma Rousseff” (FISHER, 2018, p. 9). A Atlas apoiou mobilizações contra esse governo seja na divulgação das manifestações no seu website, seja na presença física de seus dirigentes nessas manifestações. Conforme enfatiza Chafuen (2017 apud FANG, 2017), "surgiu uma abertura - uma crise - e uma demanda por mudanças, e nós tínhamos pessoas treinadas para pressionar por certas políticas”.

Suas estratégias contam com uma série de atividades pedagógicas, ou “colonização pedagógica” (JAURETCHE, 1975), que objetivam “educar economicamente” outras sociedades (ATLAS, 2019) através de recursos materiais e simbólicos que visam universalizar os interesses da classe dominante na forma de consenso. A exemplo dessas atividades, há a divulgação de livros, organização de eventos e criação de projetos que vinculam uma ampla rede de organizações internacionais. Esses institutos liberais objetivam auferir uma maior coesão de suas propostas e atividades, de modo a difundir suas agendas neoliberais na sociedade e contribuir para a implementação de reformas políticas e econômicas de livre mercado no país, formando um elo entre sociedade civil e o âmbito político. Funciona, como nos alerta Bourdieu (1998, p. 28), enquanto uma espécie de “gota-a-gota simbólico”, na qual a Atlas e seus institutos parceiros contribuem para que os preceitos neoliberais sejam vistos sob a aparência da inevitabilidade.

Essa instituição (e seus institutos parceiros) é mantida pelas doações generosas de grandes empresários como os irmãos Koch e de grandes empresas como Exxon Mobil, MasterCard e Philip Morris. Outros gigantes como Pfizer, Procter e Gamble e Shell financiaram sua viabilização quando da sua criação (FANG, 2017). Em uma de suas palestras, o presidente da Atlas explicou a falta de publicidade quanto aos recursos advindos de grandes empresas:

A Pfizer não pode patrocinar pesquisas sobre temas de saúde, nem a Exxon pode pagar sobre temas meio ambientais, mas os think tanks libertários de ultradireita, como os da Rede Atlas, não só podem essas pesquisas com mais credibilidade como fazê-lo de forma a obter cobertura dos meios de comunicação (CHAFUEN, 2017 apud AHARONIAN; RANGEL, 2018).

Mesmo não se vinculando diretamente aos objetivos estratégicos do governo dos Estados Unidos, ao receber apoio financeiro advindo de organismos privados vinculados à Washington (a exemplo do NED), a Atlas atua enquanto extensão tácita da política externa estadunidense contribuindo para a promoção de políticas neoliberais e na desestabilização daqueles governos que desafiem a hegemonia estadunidense - algo já recorrente na história da América Latina. Por intermédio da institucionalização de diferentes organismos, a classe dominante estadunidense logrou alcançar difusão e naturalização de uma ordem própria, atendendo os seus interesses econômicos dominantes. Assim,

A expansão política dos Estados Unidos também pretende expandir o neoliberalismo. E expandir o neoliberalismo promove e ajuda a estabilizar o projeto de consolidação da hegemonia política estadunidense em todo o mundo mediante o recrutamento de grupos de adeptos que se beneficiam materialmente com tal expansão (VANAIK, 2010, p. 12).

Nesse sentido, a constituição do NED, substituindo as ações militares anteriormente desenvolvidas pela Agência Central de Inteligência dos EUA, é peça fundamental na condução dessa expansão.

National Emdowment for Democracy (NED)

Com o fim da Guerra Fria, iniciava-se um processo de readaptação da estratégia do governo dos Estados Unidos para intervir nos assuntos internos de outros países de modo "informal” fazendo uso de instituições multilaterais, organizações não governamentais e think tanks. Expressando discursos econômicos neoliberais e promovendo políticas de austeridade, essas instituições incorporam regras que facilitam a expansão e manutenção das forças sociais e econômicas dominantes. De modo mais específico, essas instituições contribuíram (e contribuem) para maior estabilidade e 
internacionalização da ordem hegemônica estadunidense estabelecida pelos interesses da classe dominante e que recebe os frutos materiais dessa expansão.

A fundação do NED em 1983 pelo então presidente Ronald Reagan foi acompanhada do surgimento de outras organizações a ela vinculadas que contribuiriam para o estabelecimento de um consenso em favor de reformas políticas e econômicas ancoradas nos interesses estratégicos dos Estados Unidos, em especial na América Latina. Dentre elas: a) Center for International Private Enterprise (CIPE), organização empresarial vinculada a mais de 100 associações empresariais no mundo; b) National Democratic Institute for International Affairs (NDI), instituto associado ao Partido Democrata; c) International Republican Institute (IRI) associado ao Partido Republicano; e d) o American Center for International Labor Solidarity (ACILS) com atuação nos setores trabalhistas e sindicais (CASIMIRO, 2015). Nesse sentido, "O NED serviria como a organização guarda-chuva através da qual esses quatro grupos e um número crescente de outros grupos do setor privado receberiam financiamento para realizar programas no exterior” (NED, 2019).

A constituição desse instituto se deu de forma que pudesse substituir as ações anteriormente desenvolvidas pela CIA, em especial no que compete ao financiamento de grupos contrarrevolucionários. Nesse sentido, o estabelecimento de políticas e agendas neoliberais tornaram-se foco importante enquanto emulava os processos de democratização na América Latina. Com recursos advindos majoritariamente do Congresso dos Estados Unidos (que aprova os recursos enviados pelo Departamento de Estado), o NED desembolsa financiamentos para projetos de diferentes organizações em 90 países. Seu foco de atuação se baseia em instituições no exterior que fortaleçam os "ideais e valores democráticos”, as “organizações da sociedade civil”, a “educação cívica”, “instituições e processos políticos democráticos” e "economia de mercado de ampla cobertura” (NED, 2019). Só na América Latina em 2019, o NED financiou 237 projetos no valor total de US\$ 25.639.175,00 (NED, 2019) De fato, “o NED permite desenvolver políticas que normalmente seriam impedidas por princípios de soberania e não-intervenção, e essa “diplomacia informal” é um elemento potencialmente útil para a política externa” (SCOTT; WALTERS, 2000, p. 255).

Para Minella (2009), a estrutura do NED representa uma articulação importante entre o governo estadunidense, os dois principais partidos políticos, as corporações estadunidenses e a cúpula do movimento sindical. A conformação deste quadro de organizações privadas, possibilitaria que os Estados Unidos continuassem a estender e consolidar os seus interesses no exterior mediante uma espécie de diplomacia informal, permitindo que tais ações não fossem vinculadas, ao menos diretamente, à imagem desse. Como observa um antigo Vice-Presidente do NED (1989-2016),

Como organização não-governamental [o NED], poderia fornecer assistência política às forças democráticas em situações políticas repressivas ou outras situações políticas sensíveis, em que o apoio do governo dos EUA, mesmo quando canalizado por instituições intermediárias não governamentais, seria diplomática ou politicamente inviável (LOWE, 2008 apud NED, 2019).

Assim, foi possível incluir a participação de atores menos tradicionais da política externa dos Estados Unidos, como as organizações da sociedade civil no âmbito dos institutos (neo)liberais, conforme fluxograma abaixo:

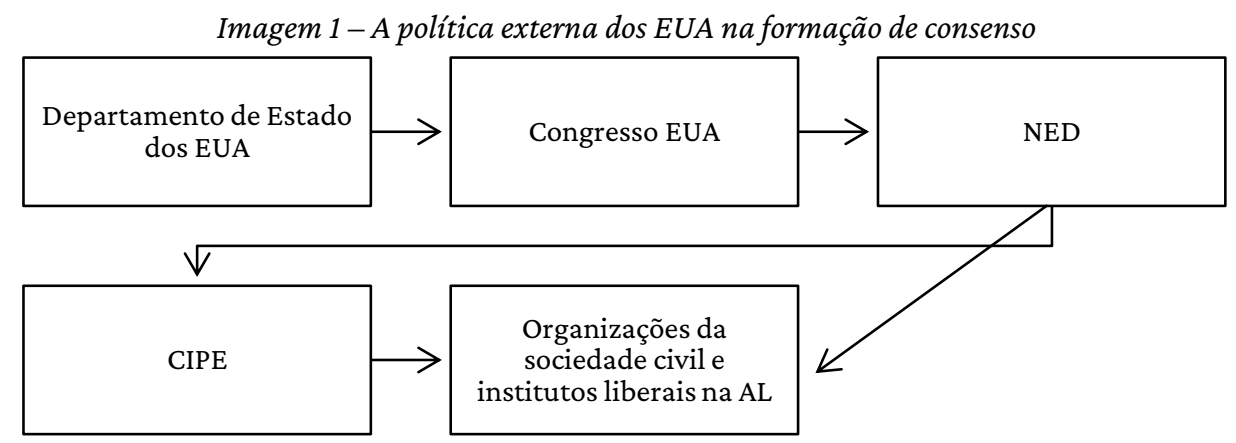

Fonte: Elaborado pelos autores. 
Embora afirme que não é dotada e não aceita financiamento do governo, existem evidências que apontam para o recebimento por parte da Atlas, e/ou de seus institutos parceiros, de recursos advindos de organismos como o NED e o CIPE (FISHER, 2018, p. 11). A relação entre a Atlas e o NED se tornou pública com a chegada da economista e atuante na Atlas, Judy Shelton, para a presidência do NED durante o governo Trump. O cordão umbilical entre essas duas instituições ainda foi fortalecido com a indicação de Matt Warner, ex-bolsista do NED, para a atual presidência da Atlas. De fato, a Atlas canaliza os fundos que recebe do NED e do CIPE transformando o dinheiro do contribuinte estadunidense em uma importante fonte de financiamento para uma rede cada vez maior (FANG, 2017). Dentre seus institutos parceiros beneficiados com fundos advindos desses organismos, pode-se mencionar o Cedice Libertad da Venezuela que teria recebido apoio do CIPE para desempenhar ações de oposição contra o Governo de Hugo Chávez (GOLINGER, 2005). Tratava-se, assim, de uma tentativa por parte do governo estadunidense de promover uma agenda neoliberal para a região, que contasse com o ímpeto de grupos de empresários e outros demais seguimentos em vista a construir um ambiente de oposição e propício para desestabilizar o governo Chávez. Com efeito, o “capital estatal” permite a classe dominante assegurar o poder sobre os diferentes tipos de capital, assim como a sua reprodução no espaço social (BOURDIEU, 1996). Esses institutos, ao difundirem os princípios pertencentes à essa classe na forma de consenso, contribuem para a manutenção de sua direção e domínio sobre o restante da sociedade inclusive no exterior. A construção do consenso, entretanto, só é alcançada se conta com o apoio de uma classe dominante local.

\section{Classe dominante local e a formação de institutos liberais no Brasil}

O número crescente de institutos liberais no Brasil parceiros da Atlas é consequência do papel direto que alguns indivíduos tiveram na construção dos primeiros institutos desse tipo no país, e do apoio do então presidente da Atlas a essa viabilização. Fez-se importante o apoio de Friedrich Hayek, que visitou o Brasil várias vezes, e Antony Fisher, criador da Atlas, para a construção de relações com membros de uma elite empresarial nacional aconselhando-os a desenvolver iniciativas em favor da disseminação das ideias liberais no país por intermédio de institutos liberais.

As viagens de Hayek ao Brasil foram realizadas a partir de patrocínios conferidos pela Revista Visão, importante mecanismo de difusão do pensamento liberal no Brasil sob a direção do empresário, engenheiro e amigo de Hayek, Henry Maksoud $^{4}$. Adentrando no meio empresarial e acadêmico, Hayek indicaria como seu principal interlocutor, Antony Fisher que, ao fundar a Atlas e o Institute of Economic Affairs (IEA), se credenciava para essa tarefa. Os primeiros nomes a procurar Fisher foram Nahum Manela, empresário do setor de roupas, e José Stelle, economista 5 , que buscavam "conselhos, contatos, expertise e apoio financeiro para sua tentativa de fundar um instituto em São Paulo” (ONOFRE, 2018, p. 283). Para a criação de uma organização desse tipo, Fisher os aconselhou a trabalhar em duas frentes: uma na busca por apoio financeiro de empresários que seriam os mantenedores desse instituto, e outra na promoção de um grupo de intelectuais liberais a que chamou de "academic advisory board" (ONOFRE, 2018). Como observa Gramsci (1989, 9), "uma das mais marcantes características de todo grupo social que se desenvolve no sentido do domínio é sua luta pela assimilação e pela conquista ideológica dos intelectuais tradicionais”. Partindo dos conselhos de Fisher, Manela tentou fundar o Instituto Brasileiro de Estudos Econômicos e Sociais (IBEPES). Contudo, desistiu do projeto por falta de recursos.

A criação de um instituto liberal no Brasil passou a ser então tratada no âmbito da Atlas. Em 1982, a Atlas apresenta relatório pessimista em relação a tentativa frustrada de conformar o IBEPES. No início de 1983, Fisher viajou ao Brasil para se reunir com Manella e com o Chicago Boy, Og Leme, assim como com grupos de empresários e estudantes. A partir destes encontros, a criação de um instituto no Brasil se materializou com o apoio do empresário Donald Stewart.

\footnotetext{
${ }^{4}$ Empresário e engenheiro, foi um dos donos da revista Visão e membro do IL-RJ e da Sociedade Mont Pelerin (CASIMIRO, 2016).

${ }^{5}$ Foi tradutor e editor de opinião da revista Visão; co-fundador do Instituto Liberal do Rio de Janeiro e coordenador da publicação de algumas das principais obras de Hayek no Brasil (FRIDERICHS, 2019).
} 
Stewart recebeu ajuda nos EUA e Reino Unido, em especial de Fisher, na arquitetura do primeiro instituto liberal brasileiro: o Instituto Liberal-RJ.

Não é claro onde começa o interesse público ou o privado nesses institutos, em sua maioria compostos e financiados por um grande número de empresários. Se não é clara essa distinção, é clara a relação desses com a Atlas, viabilizadora do embrião desse tipo de organização no país e, portanto, a simbiose entre elementos de uma classe dominante brasileira com uma estadunidense. Por fim, se há uma relação de proximidade entre a Atlas e o Departamento de Estado, há também uma relação de proximidade entre elementos parte da classe econômica dominante brasileira e dirigente - dado o alto número de membros de institutos liberais no Brasil que ascenderam à cargos no Executivo ou Legislativo (VIDAL et al, 2020). Ao fim, estamos retratando classes dominantes no Brasil e nos EUA com um mesmo interesse: o de manutenção de hegemonia e de seus privilégios a partir de práticas de consenso.

\section{Considerações finais}

Não sabemos como seria hoje a América Latina sem as intervenções diretas estadunidenses na região ao longo da Guerra Fria. Não sabemos se hoje a Guatemala teria uma sociedade mais educada e menos desigual se Arbenz não tivesse sido deposto por um conluio entre o Departamento de Estado e empresários da United Fruit Company; ou se o Brasil teria enfim realizado as reformas de base caso a Operação Brother Sam não tivesse sido concebida. Tampouco sabemos qual o real alcance das estratégias de criação de consenso na divulgação do ideário neoliberal, tendo como veículos para essa propagação os institutos liberais e, em alguns casos, estratégias de desestabilização de governos alheios aos interesses econômicos da classe dominante. O que sabemos é que não há como tratar do (sub)desenvolvimento latino-americano sem levar em consideração o papel que os Estados Unidos tiveram e ainda tem na política e na sociedade dos países latinoamericanos. As estratégias mudaram - antes mais visíveis sob a forma de coerção, hoje mais sorrateiras sob a forma de consenso - ainda assim, são estratégias de intervenção estrangeira de uma classe econômica hegemônica para manutenção de seus privilégios, só possível com o conluio dessas mesmas classes dominantes locais.

Mostrou-se que a Atlas participa diretamente e cria condições para influenciar a realidade política de diversos países na região, construindo assim um ambiente favorável para a implementação de políticas econômicas de cunho neoliberal a partir do uso de sua rede de institutos parceiros na região. Evidenciou-se ainda aproximações entre a política externa dos EUA e a atuação da Atlas. Nesse sentido, a rede Atlas enquanto aparelho privado de hegemonia e seus institutos parceiros, ao receberem apoio financeiro provindo de organismos privados dos EUA como o NED, auxiliam na promoção e na internacionalização da agenda neoliberal, assim como na desestabilização daqueles governos que se apresentam como uma ameaça a hegemonia estadunidense.

O presente trabalho, assim, visa contribuir com abordagens nas Relações Internacionais que entendem que a hegemonia no âmbito internacional está diretamente associada à aparelhos privados de hegemonia desempenhados pela classe econômica dominante e por suas redes institucionalizadas em outros países com a colaboração das classes dominantes regionais. Esse trabalho busca contribuir também com uma literatura nacional sobre os institutos liberais que objetiva vislumbrar as nuances que circundam este complexo jogo de forças no seio da sociedade, assim como as suas vinculações com forças externas que se impõe sobre a região através de um discurso neoliberal fatalista. Trata-se de, como já nos alertava Bourdieu (1998, p. 45), "mostrar como a circulação das ideias é lastreada por uma circulação de poder". Nesse sentido, trata-se do esforço em expor a rede de relações que vinculam e aproximam indivíduos com disposições e trajetórias similares, que encontram nos institutos liberais espaços fundamentais para a difusão de suas concepções de mundo e a consecução de seus interesses na sociedade.

Por fim, esse estudo busca contribuir para a reflexão acerca de práticas e conceitos como formação de consenso, hegemonia e o papel da ideologia na manutenção da estrutura econômica dominante. Além disso, nos faz questionar o 
papel predominante que o "Estado" enquanto entidade única e detentora de um "interesse nacional” recebe nessas mesmas áreas. Em específico, esse estudo nos faz retomar abordagens teóricas fundamentais para entendermos o papel das classes dominantes na criação de consenso para países e classes subalternas, com o objetivo de manutenção dessas mesmas estruturas hegemônicas.

\section{Referências}

ACHARYA, Amitav; BUZAN, Barry. Non-Western International Relations Theory. Londres: Routledge, 2010.

AHARONIAN, Aram; RANGEL, Álvaro Verzi. Rede Atlas: A Força-tarefa dos "Libertários de Ultra Direita” por uma Ofensa Capitalista na América Latina. Carta Maior, 17 agosto. 2018. Disponível em: <https://www.cartamaior.com.br/?/Editoria/Antifascismo/Rede-Atlasa-forca-tarefa-dos-libertarios-de-ultradireita-por-tras-da-ofensiva-capitalista-na-America-Latina/47/41429>. Acesso em: 22 jul. 2019.

ALPEROVITZ, Gar; DALY, Lew. Apropriação Indébita: Como os Ricos Estão Tomando a Nossa Herança Comum. São Paulo: Senac, 2010.

ATLAS NETWORK. Website oficial. Disponível em: <https://www.atlasnetwork.org/>. Acesso em: 22 jul. 2019.

ATLAS NETWORK'S CENTER FOR LATIN AMERICA. Center for Latin America. Disponível em: <https://www.atlasnetwork.org/center-for-latin-america>. Acesso em: 22 set. 2019.

BAGGIO, Kátia Gerab. Conexões ultraliberais nas Américas: o think tank norte-americano Atlas Network e suas vinculações com organizações latino-americanas. In: XII Encontro Internacional da ANPHLAC. Campo Grande, 2016. Disponível em: <http://anphlac.fflch.usp.br/sites/anphlac.fflch.usp.br/files/Katia\%20Gerab\%20Baggio\%20_Anais\%20do\%20XII\%20Encontro\%20Int ernacional\%20da\%20ANPHLAC.pdf>. Acesso em: 22 out. 2018.

BIGO, Didier. Pierre Bourdieu and international relations: Power of practices, practices of power. International Political Sociology. Oxford, v.5, n.3, p.225-258, 2011. Disponível em: <https://academic.oup.com/ips/article-abstract/5/3/225/1824487>. Acesso em: 18 nov. 2018.

BIGO, Didier; MADSEN, Mikael. Introduction to symposium “A Different Reading of the International”: Pierre Bourdieu and international studies. International Political Sociology. Oxford, v.5, n. 3, p.219-224, 2011. Disponível em: <https://academic.oup.com/ips/articleabstract/5/3/219/1824351?redirectedFrom=fulltext>. Acesso em 18 nov. 2018.

BOURDIEU, Pierre. Razões práticas sobre a teoria da ação. Campinas Papirus, 1996.

BOURDIEU, Pierre. Contrafogos: Táticas para enfrentar a invasão neoliberal. Rio de Janeiro: Zahar, 1998.

BOURDIEU, Pierre. As condições sociais da circulação internacional das ideias. Enfoques, Rio de Janeiro, v. 1 n. 01, p. 4-17, 2002. Disponível em: <https://revistas.ufrj.br/index.php/enfoques/article/view/12679/8870>. Acesso em: 10 maio. 2019.

BOURDIEU, Pierre; WACQUANT, Loïc. An Invitation to Reflexive Sociology. Chicago: The University of Chicago. 1992.

BOURDIEU, Pierre; WACQUANT, Loïc. Sobre as Artimanhas da Razão Imperialista. Estudos Afro-Asiáticos, Rio de Janeiro, v. 24, n. 1, p. 15-33, 2002. Disponível em: <http://www.scielo.br/scielo.php?script=sci_arttext\&pid=S0101-546X2002000100002>. Acesso em: 10 maio. 2019.

BRZEZINSKI, Zbigniew. El gran tablero mundial. La supremacia estadounidense y sus imperativos geoestratégicos. Barcelona: Paidós, 1998.

CASIMIRO, Fernando Henrique. Globalização e o Capital-Imperialismo: a articulação de organizações patronais latino-americanas em rede associativa, nos anos de 1990. In XXVII Simpósio Nacional de História, 2015, Florianópolis. Disponível em: <http://www.snh2015.anpuh.org/resources/anais/39/1427545459_ARQUIVO_ArtigoAnpuh2015.pdf>.Acesso em 12 jul. 2019.

CASIMIRO, Fernando Henrique. A Nova Direita no Brasil: aparelhos de ação político-ideológica e a atualização das estratégias de dominação burguesa. Tese Doutorado em História Social. Rio de Janeiro: Universidade Federal Fluminense, 2016.

COX, Robert. Social Forces, States and World Orders: Beyond International Relations Theory. Millenium. v. 10, n. 2, p. 126-155, 1981. Disponível em: <https://journals.sagepub.com/doi/abs/10.1177/03058298810100020501?journalCode=mila >. Acesso em: 30 ago. 2018.

COX, Robert. Gramsci, Hegemony and International Relations: A essay in method. In GILL, Stephen (ed.). Gramsci, Historical Materialism and International Relations. Cambridge: Cambridge University Press, 1993, cap. 2, p. 49-66.

DARDOT, Pierre; LAVAL, Christian. A Nova Razão do Mundo: Ensaio sobre a sociedade neoliberal. São Paulo: Boitempo, 2016. 
DÉZALAY, Yves. Les courtiers de l'international. Héritiers cosmopolites, mercenaires de l'impérialisme et missionnaires de l'universel. Actes de la recherche en sciences sociales, n.151, p.151-152, 2004. Disponível em: $<$ https://dialnet.unirioja.es/servlet/articulo?codigo=839735 >. Acesso em : 22 set. 2018.

EAGLETON, Terry. A Ideologia e suas vicissitudes no Marxismo ocidental. In: ZIZEK, Slavoj (org.). Um Mapa da Ideologia. Rio de Janeiro: Contraponto, 1996.

FANG, Lee. Esferas de Influência. The Intercept, 11 agosto, 2017. Disponível em: $<$ https://theintercept.com/2017/08/11/esfera-deinfluencia-como-os-libertarios americanos-estao-reinventando-a-politica-latino-americana/>. Acesso em: 12 jan. 2018.

FISCHER, Karin; PLEHWE, Dieter. Redes de Think Tanks e Intelectuales de Derecha en América Latina. Nueva Sociedad, n. 245, maio-junho 2013, p.70-86. Disponível em: <https://nuso.org/media/articles/downloads/3941_1.pdf>. Acesso em 20 mar. 2019.

FISCHER, Karin. A Rede Atlas: Espalhando think tanks de livre mercado pelo mundo. Diálogo Global. v. 8, ago. 2018, p. 10-12. Disponível em: <http://globaldialogue.isa-sociology.org/wp-content/uploads/2018/09/v8i2-portuguese.pdf $>$. Acesso em $20 \mathrm{mar}$. 2019.

FRIDERICHS, Lidiane. A atuação política dos Think Tanks neoliberais brasileiros e argentinos: Os casos do Instituto Liberal, do Instituto De Estudos Empresariais e do Instituto para el Desarrollo Empresarial de la Argentina (1983-1998). Tese Doutorado em História. São Leopoldo: Universidade do Vale do Rio dos Sinos. 2019.

GILL, Stephen. Gramsci and global politics: towards a post-hegemonic research agenda. In: GILL, Stephen (ed.). Gramsci, Historical Materialism and International Relations. Cambridge: Cambridge University Press, 1993, p. 1-18.

GILL, Stephen. The contradictions of US supremacy. In: PANITCH, Leo; LEYES, Colin. The socialist register: The empire reloaded. London: Merlin, 2005.

GILL, Stephen. Power and Resistance in the New World Order. New York: Palgrave Macmillan, 2008.

GOLINGER, Eva. O Código Chávez. Caracas: Monte Ávila Editores, 2005.

GRAMSCI, Antonio. Selections from the Prision Notebooks. New York: International Publishers, 1971.

GRAMSCI, Antonio. Intelectuais e a Organização da Cultura. São Paulo: Civilização Brasileira, 1989.

GRAMSCI, Antonio. Cadernos do Cárcere. v.1. Rio de Janeiro: Civilização Brasileira, 1999.

GRAMSCI, Antonio. Cadernos do Cárcere. vol.2. Rio de Janeiro: Civilização Brasileira, 2001.

GRAMSCI, Antonio. Cadernos do Cárcere. vol.5. Rio de Janeiro: Civilização Brasileira, 2002.

GRAMSCI, Antonio. Cadernos do Cárcere. v.3. Rio de Janeiro: Civilização Brasileira. 2007.

HOFFMAN, Stanley. An American Social Science: International Relations. Daedalus. n. 106 v.3, 1977, p. 41-6. Disponível em: <https://www.amherst.edu/system/files/media/0084/Hoffman.pdf >. Acesso em: 20 jun. 2019.

JAURETCHE, Arturo. Los Profetas del Odio y la Yapa: La Colonización Pedagógica. Buenos Aires: Pena Lillo, 1975.

MCGANN, James; WEAVER, Kent. (eds.). Think Tanks and Civil Societies: Catalysts for ideas and action. Londres: Transactions Publishers, 2002.

MINELLA, Ary Cesar. Construindo hegemonia: Democracia e livre mercado. Caderno CRH, Salvador, v. 22, n. 55, p. 13-40, 2009. Disponível em: $<$ http://www.scielo.br/scielo.php? script=sci_abstract\&pid=S0103-

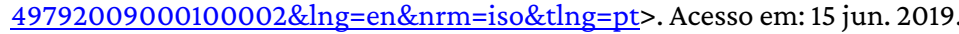

NATIONAL ENDOWMENT FOR DEMOCRACY. Website NED. 2019. Disponível em: <https://www.ned.org/about/history/>. Acesso em: 22 jul. 2019

ONOFRE, Gabriel da Fonseca. O papel de intelectuais e think tanks na propagação do liberalismo econômico na segunda metade do século XX. Tese de Doutorado em História. Niterói: Universidade Federal Fluminense, 2018.

PIKETTY, Thomas. Capital and Ideology. Londres: Harvard University Press, 2020.

SCOTT, James.; WALTERS, Kelly. Supporting the wave: western political foundations and the promotion of a global democratic society. Global Society, New Jersey, v. 14, n. 2, 2000, p. 237-257. Disponível em:

<https://www.tandfonline.com/doi/abs/10.1080/13600820050008467>. Acesso em: 02 jul. 2019.

TICKNER, Arlene. Seeing IR Differently: Notes from the Third World. Millenium. N.32 vol.2, 2003, p. 295-324. Disponível em: $<$ https://www.researchgate.net/publication/258171212_Seeing_IR_Differently_Notes_from_the_Third_World >. Acesso em: 10 jun. 2019. 
TICKNER, Arlene; INOUE, Cynthia. Many Worlds, Many Theories? Revista Brasileira de Política Internacional. v.2, n.59, 2016 , p. 1-4. Disponível em: > http://www.scielo.br/scielo.php?script=sci_arttext\&pid=S0034-73292016000200101>. Acesso em: 05 jun. 2019.

VANAIK, Achin. Casus belli: cómo los Estados Unidos venden la guerra. Transnational Institute, 2010.

VILLA, Rafael Duarte; TICKNER, Arlene; SOUZA, Marília; MASMEDA, Yamile. Comunidades de Relações Internacionais na América Latina: Uma Análise das Tendências a partir do TRIP 2014. Carta Internacional. v.1, n.12, 2017, p. 224-256. Disponível em:

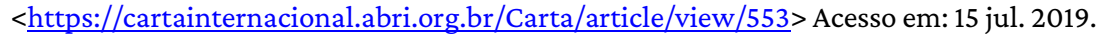

VIDAL, Camila; LOPEZ, Jahde; BRUM, Luan. The power of ideas. Revista Contexto Internacional, Rio de Janeiro, v 42, n,1, Jan/abr, 2020.

Funções de colaboração exercidas

Camila Feix Vidal Conceituação; Metodologia; Validação; Curadoria de dados; Administração do projeto; Visualização; Análise formal; Recursos; Obtenção de financiamento; Software; Investigação; Supervisão; Escrita (primeira redação); Escrita (revisão e edição); Curadoria de dados; Visualização; Sofware; Escrita (primeira redação); 